\title{
Spectroscopic ellipsometry investigation to study the microstructure evolution in boron-doped amorphous silicon films as a result of hydrogen dilution
}

\author{
Venkanna Kanneboina ${ }^{1}$ (D) Pratima Agarwal ${ }^{1,2}$
}

Received: 20 November 2020 / Accepted: 9 March 2021 / Published online: 24 March 2021

(c) The Author(s) 2021 OPEN

\begin{abstract}
Spectroscopic ellipsometry (SE) is a sophisticated technique to find the optical constants, bandgap and microstructure of thin layer. SE is used to study the microstructure evolution in boron-doped amorphous silicon films for different hydrogen flow rates (HFR). Spectral dependance of the real and imaginary parts of pseudo-dielectric constant is obtained at a fix angle of incidence $\left(70^{\circ}\right)$. Tauc-Lorentz (T-L) optical model is used to estimate the thickness, bandgap, optical constant and thickness of the top rough layer of the films, whereas Bruggeman effective medium approximation (BEMA) is applied to find the volume fractions of amorphous, crystalline and void phases. A shift in peak position from 3.65 to $4.1 \mathrm{eV}$ in dielectric constant is observed as the hydrogen flow rate is increased from 30 to 70 SCCM. This is accompanied by the emergence of a peak near $3.4 \mathrm{eV}$, which belongs to the direct bandgap of $\mathrm{c}-\mathrm{Si}$. These observations suggest an improvement in microstructure of the films deposited at higher HFR. It is also supported by the observation that films deposited at higher HFR have higher magnitude of amplitude parameter and less broadening. Fitting of experimental data using BEMA also suggests that crystalline fraction increases and amorphous fraction decreases at higher HFR. The bandgap and thickness of top rough layer estimated from SE data are matched well with those obtained using transmission data and atomic force microscopy.
\end{abstract}

Keywords Boron-doped a-Si:H films · Hydrogen dilution · Microstructural and optical properties · Ellipsometry · Solar cells

\section{Introduction}

The quality of a-Si:H(p) layer is very crucial to improve the efficiency of a-Si:H(p)/c-Si(n) heterojunction $(\mathrm{HJ})$ solar cells, which have demonstrated very promising performance [1-4]. The optical and electronic properties of a-Si:H(p) films are affected significantly by process conditions like deposition temperature, chamber pressure and flow rates of hydrogen and silane gases, hydrogen dilution, etc. Though a number of studies have reported the influence of deposition parameters on the quality of a-Si:H(i) films [5-8], however, very few research groups have focussed on a-Si:H(p) films [9-12]. The a-Si:H(n) thin films have been also optimized for the application of back surface field of the solar cells by varying hydrogen dilution and flow rate [13-17]. It is commonly observed for the intrinsic as well as doped p/n-type a-Si:H films that the density and microstructure of the films have improved depending on hydrogen dilution during the deposition of the films.

The $\mathrm{p}$-layer in a-Si:H-based solar cells should have low resistivity, low activation energy and large bandgap [18] to reduce the series resistance and increase the builtin potential, respectively. Larger bandgap helps more light to pass through the $\mathrm{p}$-layer to absorber c-Si layer,

$\checkmark$ Venkanna Kanneboina, drkvenkannahs@smec.ac.in | 'Department of Physics, Indian Institute of Technology Guwahati, Assam 781039, India. ${ }^{2}$ Centre for Energy, Indian Institute of Technology Guwahati, Assam 781039, India. 
thus increasing the short-circuit current [18]. This can be achieved by tuning the deposition parameters, such as hydrogen flow rate, substrate temperature and $\mathrm{rf}$ power [19]. The a-Si:H films transform into hydrogenated poly/ nano/micro-crystallite silicon phase for different hydrogen dilution of silane. Moreover, hydrogen has significant impact on the microstructure, defect density, optical and electrical properties by reducing the fraction of weak or strained $\mathrm{Si}-\mathrm{Si}$ bonds and passivating the un-coordinated/ dangling bonds $[20,21]$. The SE is one of the finest techniques to evaluate microstructural changes and optical properties of the silicon thin films. In situ and ex situ SE techniques are used for intrinsic a-Si:H films to study the optical properties and to estimate thickness of the films [22-30]. However, very few studies have been reported on doped a-Si:H films by SE measurements $[13,23,28$, $30,31]$. It is very important to understand the properties of the doped a-Si:H films along with intrinsic films. Work presented in this paper helps to understand the microstructural and optical properties of the doped films as a function of hydrogen dilution for improvement in performance of the solar cells.

This paper presents the effect of hydrogen flow rate (HFR) on microstructural and optical properties of a-Si:H(p) films. It is of great importance to understand the microstructure, deposition rate, defects and optical properties of $\mathrm{a}-\mathrm{Si}: \mathrm{H}(\mathrm{p})$ films on deposition parameters to fabricate and achieve high efficiency of silicon heterojunction (SHJ) solar cells. Thickness, bandgap and roughness of these films are determined using T-L model to analyse the SE data, whereas BEMA is used to find the amorphous, crystalline and void volume fractions. SE results are compared with UV-Vis-NIR and AFM results.

\section{Experimental details}

Hydrogenated amorphous silicon films with boron doping are prepared on Glass (Corning-1737) substrates for different hydrogen flow rate (HFR) (30 to $70 \mathrm{SCCM}$ ) in a multichamber PECVD system using $13.56 \mathrm{MHz}$ radio frequency and $30 \mathrm{~W}$ power. Pure silane $\left(\mathrm{SiH}_{4}\right)$ flow rate is maintained at 4 SCCM. The deposition temperature and chamber pressure are held at $200{ }^{\circ} \mathrm{C}$ and $0.42 \mathrm{mbar}$, respectively, for all films. Diborane ( $2 \%$ of $\mathrm{B}_{2} \mathrm{H}_{6}$ and $98 \%$ of $\mathrm{H}_{2}$ ) at a flow rate of 6 SCCM has been used for p-type doping of a-Si:H thin films. The films were deposited for 15 min only. The films labelled as MP120-MP124 correspond to a-Si:H(p) with HFR of 30-70 SCCM, respectively.

The a-Si:H(p) thin films were characterized by SE (Semilab, Sopra, GES5) techniques in the spectral energy range from 2.0 to $5.50 \mathrm{eV}$ and angle of incidence of $70^{\circ}$. Analysis of the SE data was done using SEA software. Recording of the SE spectra of a-Si:H films deposited by PECVD and c-Si wafer after cleaning was done with Semilab (Sopra, GES5) spectrometer and recorded data were converted into $n-k$ file using SEA software. These $n-k$ files of a-Si:H and c-Si were used for estimating volume fractions of amorphous and crystalline phases in the films. These converted $n-k$ files were compared with default $n-k$ data of SEA software. Optical transmittance of the films was measured in the range 200-2500 nm (Perkin Elmer Lambda 900) to find out the thickness as well as optical bandgap of the films. The surface morphology and roughness were estimated using AFM (Agilent 5500).

\section{Results and discussion}

\subsection{Spectroscopic ellipsometry studies}

Variation of dielectric constant $\left(\left\langle\varepsilon_{1}\right\rangle\right)$ and $\left(\left\langle\varepsilon_{2}\right\rangle\right)$ with photon energy for boron-doped a-Si:H films is shown in Fig. 1. The corresponding spectra for crystalline silicon (normalized after dividing by a factor of two) are also added for reference purpose. These $\left\langle\varepsilon_{1}\right\rangle$ and $\left\langle\varepsilon_{2}\right\rangle$ are real and imaginary parts of pseudo-dielectric function of a-Si:H(p) films, respectively. The interference of reflected light from different surfaces results in a peak in spectra at around $2.0 \mathrm{eV}$ which is moved from 2 to $2.5 \mathrm{eV}$ at higher HFR. This shift in peak position at low energy is because of different thickness of the films for different hydrogen flow rate. For crystalline silicon, the peaks and dips in $\left\langle\varepsilon_{1}\right\rangle$ and two distinguished peaks in $\left\langle\varepsilon_{2}\right\rangle$ at $3.40 \mathrm{eV}$ and $4.20 \mathrm{eV}$ are due to direct band transitions [32, 33]. In the case of $\mathrm{c}-\mathrm{Si}$, the pseudo-dielectric function $(\langle\varepsilon\rangle)$ reduces to the dielectric function $(\varepsilon)$ of the material when the films are very thick as well as have smooth surfaces. Similar kind of peaks with high intensity has been observed for hydrogenated nanoand micro-crystalline silicon films $[25,33,34]$.

The $\left\langle\varepsilon_{2}\right\rangle$ spectra of MP123 and MP124 films contain several peaks at different positions, and thus, broad spectra are observed. The spectra are deconvoluted into three characteristic peaks positioned at 3.2, 3.6 and $4.2 \mathrm{eV}$ as shown in Fig. 1c. The $\left\langle\varepsilon_{2}\right\rangle$ spectra of MP123 film were deconvoluted in the energy range of $2.5-5.5 \mathrm{eV}$ to mainly focus on three distinct peaks. The baseline correction was done during deconvolution. That is the reason the spectra (in Fig. 1c) appear to approach zero. The deconvolution was done to identify the peak positions which are given as initial values for fitting the experimental data (Fig. 1c). The peaks at 3.2 and $4.2 \mathrm{eV}$ are due to nano/micro-crystalline nature, whereas peak at $3.6 \mathrm{eV}$ corresponds to amorphous behaviour of the a-Si:H films [23, 29, 35-37]. Observed peak at $3.2 \mathrm{eV}$ is slightly shifted from $3.4 \mathrm{eV}$ due to small 

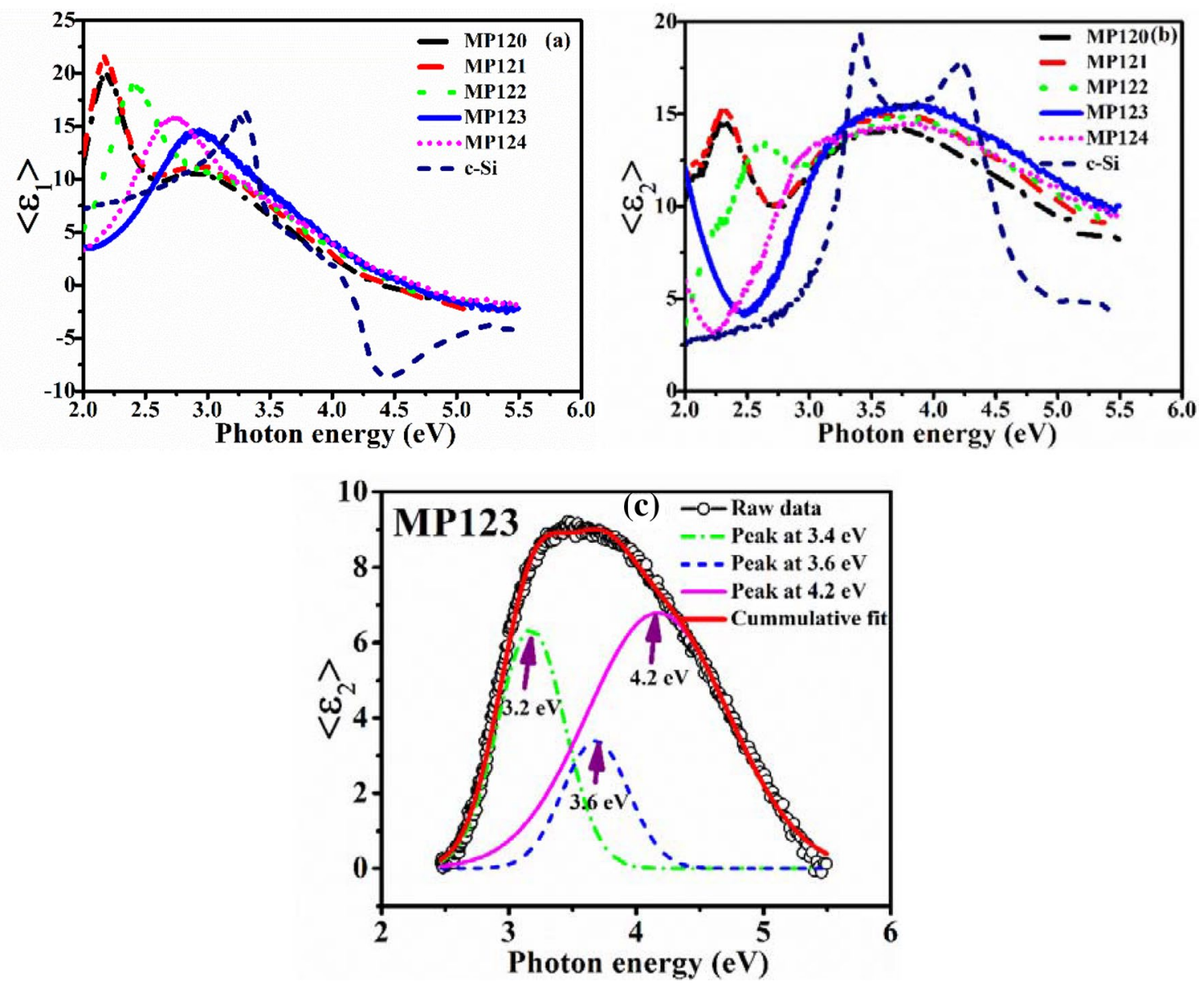

Fig. 1 (a-c) Measured dielectric functions with variation of photon energy of a-Si:H(p) thin films as well as crystalline silicon (crystalline silicon curve is normalized by a factor of two to fit in the graph). c

crystallite size of MP123 and MP124 films. The amplitudes of $\left\langle\varepsilon_{1}\right\rangle$ and $\left\langle\varepsilon_{2}\right\rangle$ are highest for MP123 film.

These observations suggest that the microstructure is changed from amorphous to near nanocrystalline nature $[23,24,31,38-40]$. The amplitude of $\left\langle\varepsilon_{2}\right\rangle$ spectra has increased systematically from MP120 to MP123 films, whereas it is slightly decreased for MP124 film. The amplitude of $\left\langle\varepsilon_{2}\right\rangle$ spectrum indicates the density and percentage of voids in the film, which depends upon the concentration of different $\mathrm{H}$-bonding configurations in a-Si: $\mathrm{H}$ films [32]. Higher amplitude and less broadness in these curves is an indication of higher density and less disorder with increase in HFR. This film (MP123), deposited using 60 SCCM of hydrogen flow rate, also shows least void fraction when SE spectra are fitted using BEMA. The deposition conditions are best suited for fabrication of $\mathrm{c}-\mathrm{Si}(\mathrm{n}) /$ a-Si:H(p) HJ solar cells.

Thickness and bandgap of the films are estimated using the T-L optical model $[23,28,30,35,36]$. Two layers' structure (substrate/bulk a-Si:H-layer/rough surface a-Si:H-layer/
Deconvolution spectra of MP123 to identify the peak positions for initial values for fitting

air) was used to calculate these values. No oxide layer is assumed in this picture for two reasons: (1) the thickness of oxide layer is usually very small ( 1 to $2 \mathrm{~nm}$ ), and (2) it further complicates the fitting procedure. Most of the reports in the literature also do not include the oxide layer while fitting the SE spectra. The backside of the glass substrate was smooth enough, and the value of $\varepsilon_{\infty}$ was fixed at 1 during $T-L$ model fitting. Further the same two-layer model is also used for BEMA to evaluate the volume fraction of different phases; void, amorphous and crystalline and top surface layer roughness of these films. T-L optical model is mainly used to calculate the bandgap, optical constants and thickness of films, whereas BEMA model is used to determine the void, amorphous and crystalline fraction in mixed and nanocrystalline films. These details are presented in our earlier publications $[41,42]$. Figure $2 a$, $\mathrm{b}$ shows the measured spectra of $\left\langle\varepsilon_{1}\right\rangle$ and $\left\langle\varepsilon_{2}\right\rangle$ of films and fitted with T-L model. Calculated values of thickness and optical bandgap are given in Table 1. The fitted spectra match well with the measured one. 

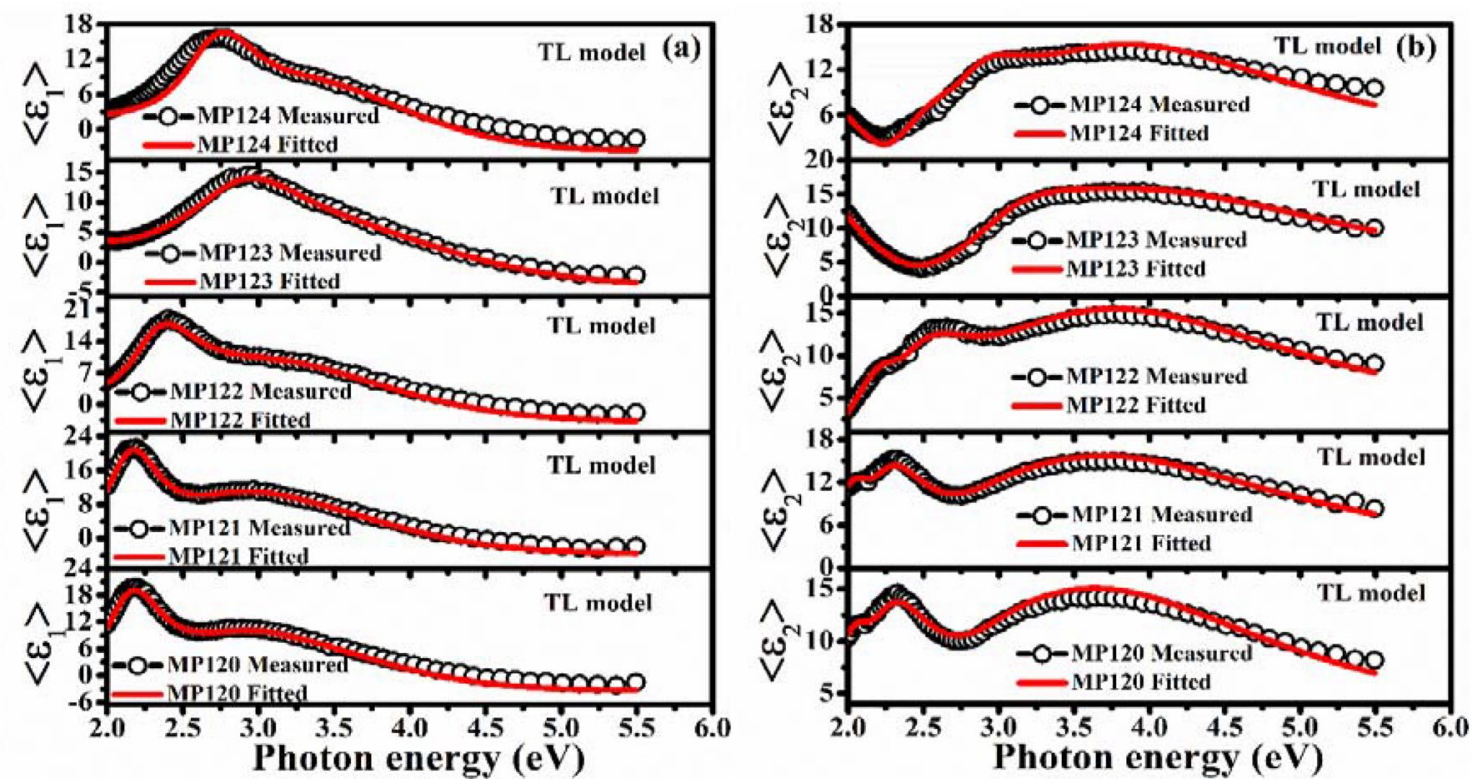

Fig. 2 Spectral dependence of $\left\langle\varepsilon_{1}\right\rangle$ and $\left\langle\varepsilon_{2}\right\rangle$ of a-Si:H(p) films. The recorded spectra are represented by symbols, and line represents the T-L model fit

Table 1 Thickness and estimated parameters of $A, E_{0}, C$ and $E_{\mathrm{g}}$ a-Si:H(p) films by $\mathrm{T}-\mathrm{L}$ model

\begin{tabular}{llllllllll}
\hline Sample & HFR $(\mathrm{SCCM})$ & Thickness $(\mathrm{nm})$ & $A(\mathrm{eV})$ & $E_{0}(\mathrm{eV})$ & $C(\mathrm{eV})$ & $E_{\mathrm{g}}(\mathrm{eV})$ & $d_{\mathrm{s}}(\mathrm{nm})$ & $\begin{array}{l}E_{\mathrm{g}}(\mathrm{eV}) \\
\text { (UV-Vis- } \\
\text { NIR) }\end{array}$ & $R^{2}(\%)$ \\
\hline MP120 & 30 & 105 & 176 & 3.65 & 2.99 & 1.82 & 2.09 & 1.81 & 99.74 \\
MP121 & 40 & 105 & 193 & 3.75 & 2.90 & 1.82 & 1.82 & 1.82 & 99.68 \\
MP122 & 50 & 92 & 194 & 3.72 & 2.85 & 1.84 & 1.11 & 1.83 & 99.05 \\
MP123 & 60 & 74 & 210 & 3.99 & 2.67 & 1.85 & 1.50 & 1.85 & 98.95 \\
MP124 & 70 & 67 & 186 & 4.10 & 2.79 & 1.87 & 2.16 & 1.87 & 98.12 \\
\hline
\end{tabular}

Figure 3 show the variation of different T-L model fitting parameters with HFR along with the approximate error bars. As was qualitatively predicted, higher HFR improves the microstructural properties of the films, thus increasing the amplitude $(A)$ and lowering the broadening (C). However, when the HFR is quite high (70 SCCM, MP124), the trend is reversed; i.e. $A$ is slightly reduced, whereas $C$ is little higher. These results could be understood in terms of the change in atomic hydrogen concentration in the chamber during deposition when HFR changes. With increase in hydrogen flow rate, atomic hydrogen arriving at the surface not only breaks weak $\mathrm{Si}-\mathrm{Si}$ bonds but also diffuses in to the bulk and passivates the coordination defects, replaces weak $\mathrm{SiH}_{2}$ bonds with strong $\mathrm{Si}-\mathrm{H}$ bonds resulting in a dense structure, more ordered and relaxed network with low void fraction. This results in transformation of amorphous phase into nanocrystalline phase depending on hydrogen flow rate during deposition of the films. In a PECVD chamber, silane and hydrogen gases are dissociated into $\mathrm{SiH}_{3}, \mathrm{SiH}_{2}$ $\mathrm{SiH}, \mathrm{Si}, \mathrm{H}_{2}$ and $\mathrm{H}$ species. These reactive atoms and molecules participate in secondary phase reactions with parent $\mathrm{SiH}_{4}$ molecules mostly and then form a steady state. These secondary phase reactions have different values of rate constants $[21,43]$. The density of highly reactive $\mathrm{SiH}_{2}, \mathrm{Si}-\mathrm{H}$ and $\mathrm{Si}$ is much lesser in the plasma than $\mathrm{SiH}_{3}$, and thus, $\mathrm{SiH}_{3}$ precursor are the mainly reason to form the films on the substrates $[21,44,45]$. The $\mathrm{SiH}_{3}$ precursors start to diffuse on the surface after reaching the substrates. The grown films have weakly bonded $\mathrm{Si}-\mathrm{H}_{2}$ and strongly bonded $\mathrm{Si}-\mathrm{Si}$ and $\mathrm{Si}-\mathrm{H}$ bonds and simultaneously dangling bonds [21]. Hydrogen atoms reaching at the surface of the growing films can diffuse into the films and replace weak bonding of $\mathrm{Si}-\mathrm{H}_{2}$ with strong bonding of $\mathrm{Si}-\mathrm{H}$ and also reduce the disorder in the film by replacing overstrained $\mathrm{Si}-\mathrm{Si}$ bonds with $\mathrm{Si}-\mathrm{H}$ bonds. It also decreases the density of dangling bonds in the films. As HFR is raised, the partial pressure of hydrogen 


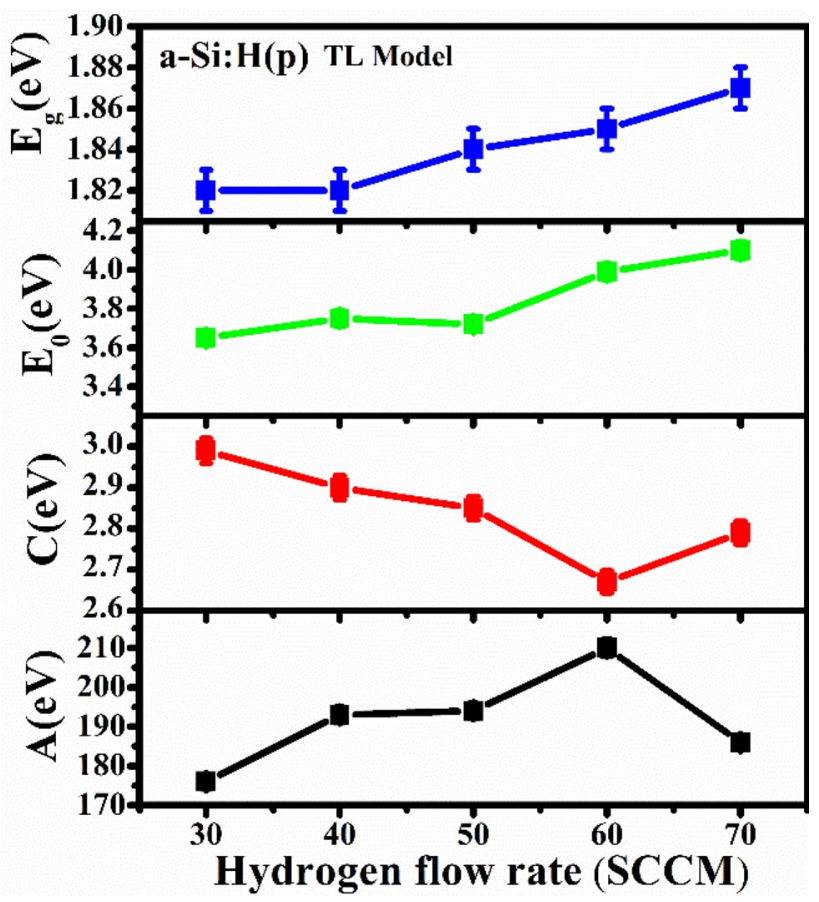

Fig. 3 Estimated parameters of $A, E_{0}, C$ and $E_{\mathrm{g}}$ with HFR of a-Si:H(p) films by $T-L$ model

in chamber also increases, resulting in a higher probability of dissociation of $\mathrm{H}_{2}$ molecules, which eventually increases the concentration of hydrogen atoms in the chamber. With initial increase in HFR, more hydrogen atoms are present, which eventually remove the coordination defects by attaching themselves to silicon dangling bonds and thus relax the structure. This also lowers the disorder in the films and thus the density of tailing states. In addition, the atomic hydrogen reaching at the surface is also able to diffuse in bulk layer and forms strong silicon-silicon and silicon-hydrogen bonds by repairing weakly formed silicon-silicon and $\mathrm{Si}-\mathrm{H}_{2}$. This further improves the structural ordering and density of the films $[36,39,46]$. However, when HFR is very high (MP124 film deposited with HFR 70 SCCM), concentration of hydrogen in the deposition chamber is significantly increased and hydrogen precursors collide with neighbouring hydrogen and silane precursors, resulting in an increase in density of defects, bond density of $\mathrm{Si}-\mathrm{H}_{2}$ and percentage of voids in the films. This is the reason of observed decrease in value of $A$ and increase in value of $C$ for MP124 film. The amplitude of $\left\langle\varepsilon_{2}\right\rangle$ is related to the film quality and the degree of disorder. As the hydrogen flow is increased, initially the disorder and defect density in the films is reduced resulting in an increase in amplitude of $\left\langle\varepsilon_{2}\right\rangle$. However, when HFR is very high (70 SCCM for MP124), the concentration of hydrogen in the deposition chamber is significantly increased and hydrogen precursors collide with neighbouring hydrogen and silane precursors, resulting in an increase in density of defects, bond density of $\mathrm{Si}-\mathrm{H}_{2}$ and percentage of voids in the films. This is the reason of observed decrease in amplitude of MP124. Results of BEMA model also suggest that crystalline fraction in these films increases and void fraction decreases as HFR is increased, whereas the amorphous fraction is more or less unchanged. However, when HFR is increased to 70 SCCM, the void fraction in the films increases at the cost of amorphous fraction.

BEMA optical model is used to determine the fraction of amorphous, crystalline and voids in the a-Si:H films $[23,28,30,41,42,47,48]$ and given in Table 2. Figure 4 shows the recorded spectra of $\left\langle\varepsilon_{1}\right\rangle$ and $\left\langle\varepsilon_{2}\right\rangle$ for these films fitted by BEMA model.

Figure 5 shows the variation of estimated fraction of $f_{\mathrm{v}}, f_{\mathrm{a}}$ and $f_{\mathrm{c}}$ of a-Si:H(p) films for different HFR. A continuous increase in $f_{\mathrm{c}}$ is observed with a drastic jump when HFR is increased to 60 SCCM. The amorphous fraction is also found decrease and void fraction to decrease, though slowly at higher HFR. The results could again be understood in terms of diffusion of atomic hydrogen on the film forming surface and in the bulk, which improves the ordering in silicon network, and thus, an increment in the crystalline fraction and decrease in void and amorphous fractions are observed. The least value of void fraction is observed for HFR 60 SCCM beyond which void fraction is increased, accompanied with a decrease in amorphous fraction. The thickness of top rough surface layer is increased as HFR increases due to higher rate if ion bombardment on the growing surface of the films. In this work, films are not completely crystallized and transformed to near nanocrystalline phase. This is the reason; we have observed very small intensity peaks at higher hydrogen dilution.
Table 2 The estimated fraction of $f_{\mathrm{v}}, f_{\mathrm{a}}$ and $f_{\mathrm{c}}$, thickness and surface roughness $\left(d_{s}\right)$ of a-Si:H(p) films

\begin{tabular}{lllrlllll}
\hline Sample & HFR $(\mathrm{SCCM})$ & Thickness $(\mathrm{nm})$ & $f_{\mathrm{v}}(\%)$ & $f_{\mathrm{a}}(\%)$ & $f_{\mathrm{c}}(\%)$ & $d_{\mathrm{s}}(\mathrm{nm})$ & $d_{\mathrm{RMS}}(\mathrm{nm})(\mathrm{AFM})$ & $R^{2}(\%)$ \\
\hline MP120 & 30 & 111 & 15.42 & 83.50 & 1.05 & 1.23 & 1.10 & 98.35 \\
MP121 & 40 & 101 & 14.85 & 84.10 & 1.05 & 1.56 & 1.27 & 98.40 \\
MP122 & 50 & 93 & 9.16 & 87.80 & 3.02 & 2.19 & 1.89 & 99.02 \\
MP123 & 60 & 73 & 7.14 & 84.35 & 8.50 & 2.46 & 2.12 & 99.45 \\
MP124 & 70 & 67 & 13.22 & 74.40 & 12.37 & 3.19 & 3.11 & 99.68 \\
\hline
\end{tabular}



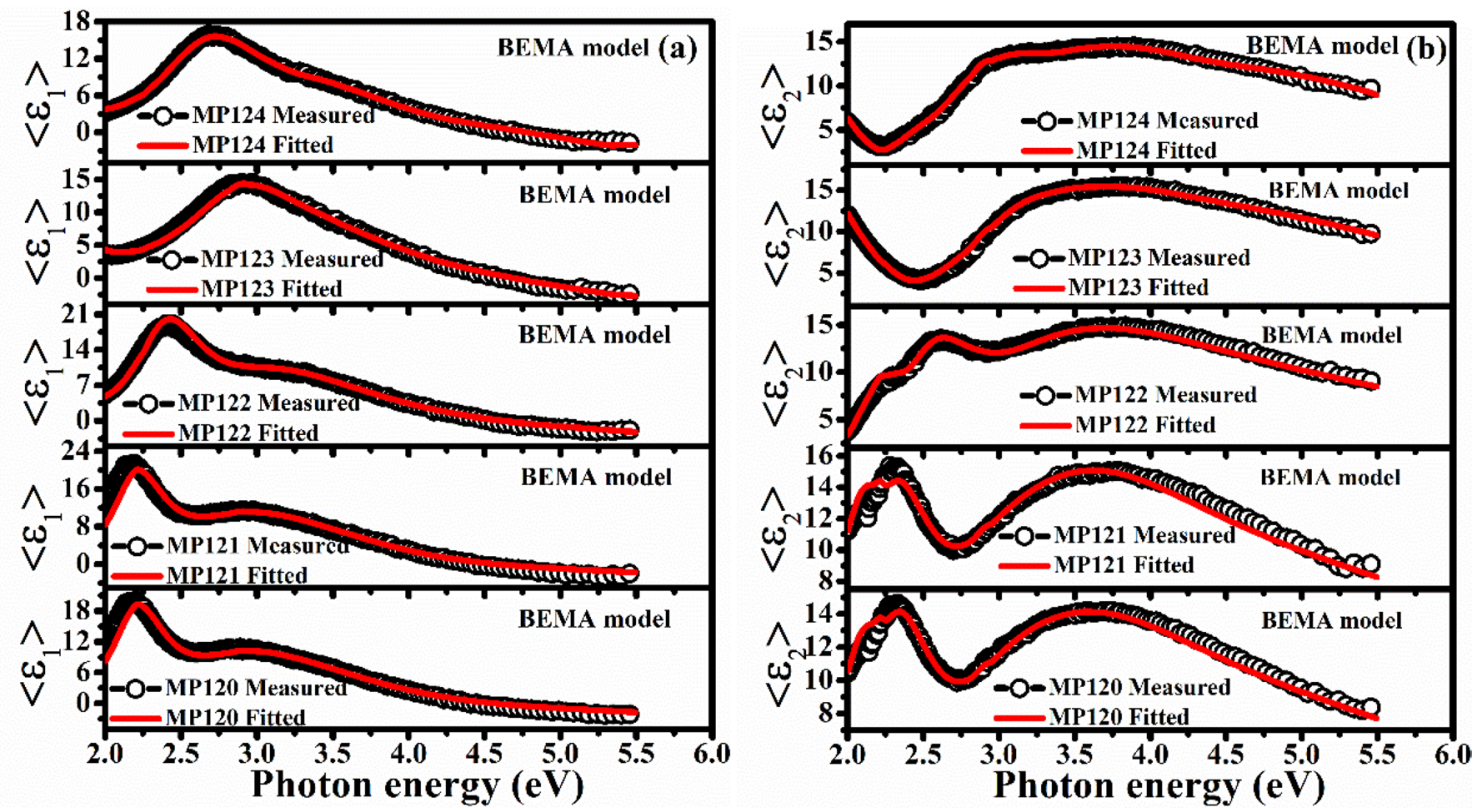

Fig. 4 (a, b) Recorded spectra of $\left\langle\varepsilon_{1}\right\rangle$ and $\left\langle\varepsilon_{2}\right\rangle$ for a-Si:H(p) films fitted by BEMA model with variation of photon energy

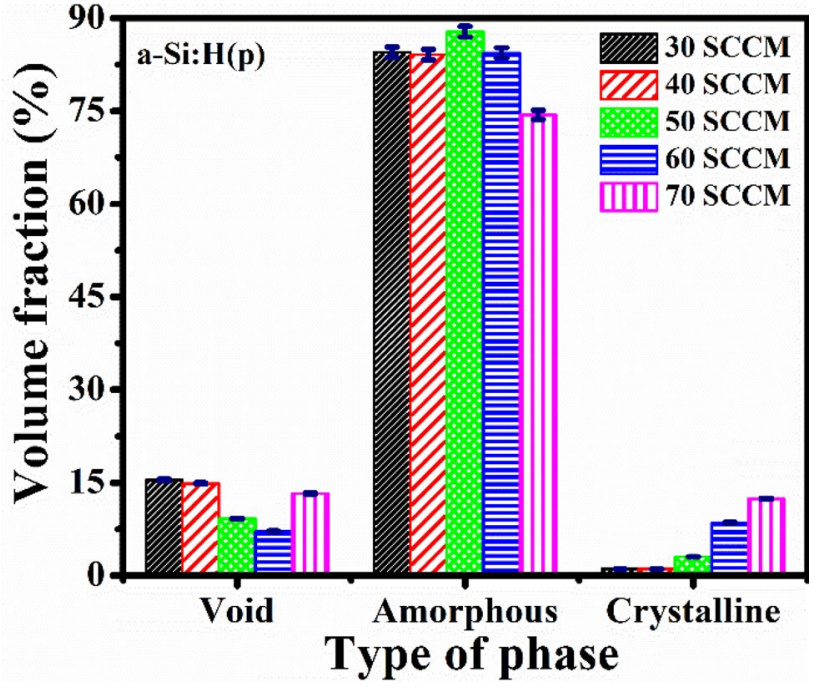

Fig. 5 Volume fractions of void, amorphous and crystalline phases at different HFR

\subsection{UV-Vis-NIR studies}

The transmission spectra of MP120-MP124 films in the wavelength range $200-2500 \mathrm{~nm}$ are shown in Fig. 6 . In Fig. 6, the absorption edge is shifted towards lower wavelength for higher HFR. The optical bandgap and thickness values, calculated from transmittance data and Tauc's plot $[49,50]$, are included in Table 1. The thickness of the films is used for calculating the absorption coefficient. Bandgap is estimated from linear fit of $\sqrt{\alpha h \nu}$ versus $h v$ plot.

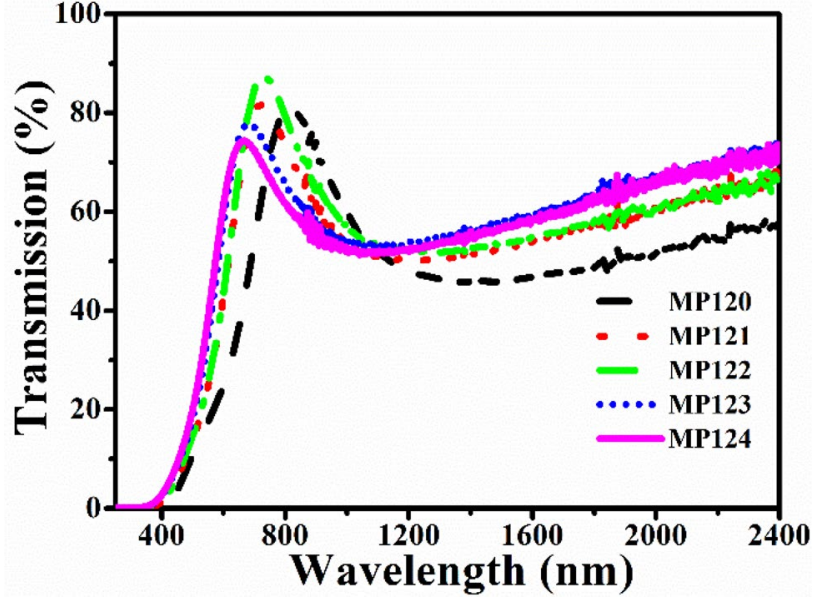

Fig. 6 UV-Vis-NIR transmittance of a-Si:H(p) thin films

These estimated values are well matched with the results obtained from SE measurements.

\subsection{AFM morphology studies}

Surface morphology of MP120-MP124 films, as measured by AFM, is shown in Fig. 7a-e. The uniformed growth throughout the sample area along with scattered voids is observed when HFR is low. The estimated RMS surface roughness $\left(d_{\text {RMS }}\right)$ values are included in Table 2 for comparison. The surface roughness values from the AFM measurements show the same trend as the values determined from SE analysis, though the absolute 

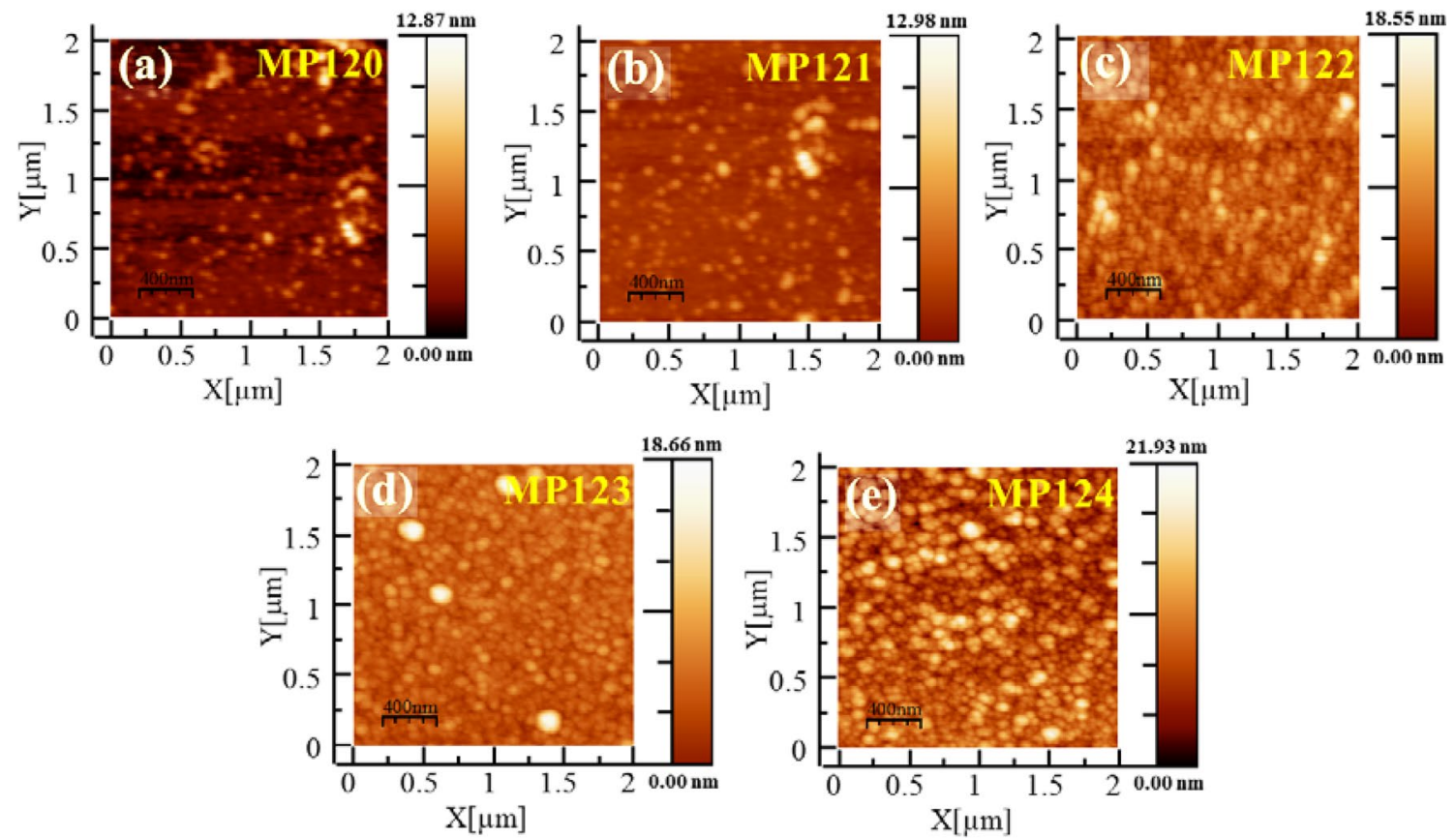

Fig. 7 (a-e) AFM surface morphology of MP120-MP124 films

values differ by a small amount. The reason for this difference could be a difference in measurement area of two methods. Similar trend is reported in the literature also. In the literature, a relationship is mentioned between surface roughness from AFM and SE as given by equation $d_{\mathrm{s}}=1.5 d_{\mathrm{rms}}+4 \AA$ [23], where $d_{\mathrm{s}}$ and $d_{\mathrm{rms}}$ are surface roughness of films that correspond to SE and AFM measurements. Our observations also follow the same trend.

In our earlier publication, we have reported the SE studies on phosphorus-doped a-Si:H thin films [14]. We have observed similar trends for a-SI:H(p) and a-Si:H(n) films, which is not very surprising as in both cases, flow rate of Silane is the main film forming precursor gas and other parameters are kept same. However, some quantitative changes are observed. Figure 8a presents a comparison in fitting parameters for SE spectra for a-Si:H(n) and a-Si:H(p) films as a function of HFR. It is observed that the bandgap of the films is same for a give HFR irrespective of whether it is $\mathrm{n}$ type or $\mathrm{p}$ type. The trends are also quite similar for other parameters like $E_{g^{\prime}} E_{0}, A$ and $C$, though the magnitudes are different. Similar trends are observed for amorphous, crystalline and void fractions also (Fig. 8b). One of the observable differences between a-Si:H(n) and a-Si:H(p) is that though for a-Si:H(n) films, absolute values of amorphous fraction are low and void fraction is high as compared to a-Si:H(p) films; the amplitude $A$ is more and $E_{0}$ is less as compared to a- $\mathrm{Si}: \mathrm{H}(\mathrm{p})$ films. It is also observed that void fraction is lesser and crystalline fraction is higher for the a-Si: $\mathrm{H}(\mathrm{p})$ thin films as compared to a-Si:H(n) films for same hydrogen flow rates.

In general, intrinsic and doped a-Si:H films have different role in solar cells. The a-Si:H(p) layer is widely used as emitter layer in solar cells, whereas a-Si:H(n) films are used as back surface field. The intrinsic layer is used as absorber layer in $\mathrm{p}$-i-n solar cells and as passivation layer in c-Si/a-Si:H solar cells, respectively. The quality of these films depends upon the hydrogen dilution as well as other parameters also. Lei Zhao et al. found that excellent wide bandgap p-type a-Si:H window layer was deposited in PECVD with low hydrogen dilution ratio of 20 , high process temperature of $220^{\circ} \mathrm{C}$ and a moderate process pressure of about $160 \mathrm{~Pa}$ [51]. The boron-doped nc-Si films were obtained by annealing at $800^{\circ} \mathrm{C}$ and it was observed that crystallinity had decreased as diborane flow rate was increased from 0.3 to $1.5 \mathrm{SCCM}$ and the boron dopants are electrically activated and subsequently occupied the lattice sites during the annealing process, which leads to increase of dark conductivity of the films [9]. The roughness of boron-doped silicon films was increased as increase in deposition time [52]. Hou et al. varied the RF power during deposition of boron-doped a-Si:H films to obtain nc-Si:H films [11]. Wang et al. deposited and controlled the different crystalline phases of the boron-doped Si films by optimizing the hydrogen dilution and power density [53]. High quality a-Si:H(p) layer with excellent optoelectronic properties is required for better performance of the solar cells. 

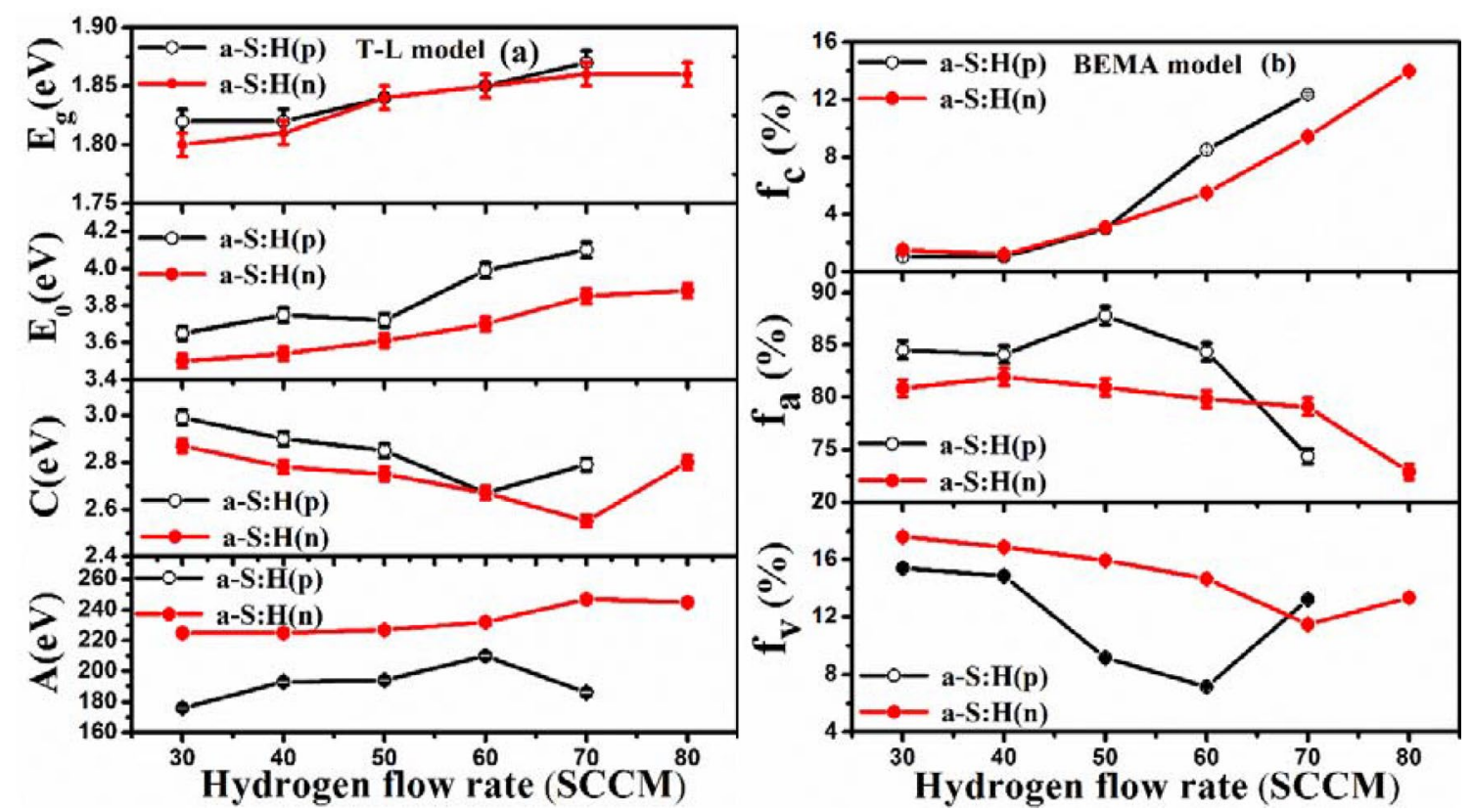

Fig. 8 (a, b) Comparison graph of boron and phosphorus-doped a-Si:H films of T-L and BEMA models by varying hydrogen flow rate

Many research groups have reported that increasing the HFR/hydrogen dilution improves the structural ordering in intrinsic a-Si:H films and films tend to become nanocrystalline/microcrystalline as the hydrogen dilution increases [7, 34, 54-59]. Similar kind of microstructural transition has been observed for $n$ and $p$-type doped a-Si:H films [9, 13, $14,17,20]$. Several groups have studied the influence of HFR on intrinsic a-Si:H films by SE measurements [34, 37, $38,40,46,60-62]$, whereas very few reported on doped a-Si:H films by SE as compared to intrinsic films $[14,28-31$, 33, 52]. Reported thickness of a-Si:H films is above $100 \mathrm{~nm}$ and it is well known that the thickness of intrinsic as well as doped a-Si:H layers is in the range of $5-20 \mathrm{~nm}$ for $\mathrm{c}-\mathrm{Si} /$ a-Si:H HJ solar cells. Our results are on the similar trends reported in the literature for intrinsic a-Si:H films. One reason for this could be that the main film forming precursor is still derived from the Silane. In our studies, we have optimized a-Si:H(p) thin films by varying hydrogen flow rate. Microstructure, optical properties and surface roughness of the prepared films were characterized by SE and compared with UV-Vis-NIR and AFM techniques. In this work, films were deposited near the onset of amorphous and nanocrystalline region by varying hydrogen flow rate for the application of solar cells. This a-Si:H(p) layer deposited near the onset of nano crystallinity improves the solar cell performance by reducing interface and bulk defect density of the films.

During growth of a-Si:H films, most of the hydrogen atoms and molecules interact with growing film and make possible chemical reactions. Three main processes take place during growth of film with hydrogen dilution; (1) hydrogen coverage on the growing surface, (2) chemical etching and cleaning, and (3) migration of adsorbed precursors on surface $[21,44]$. The atomic hydrogen diffuses on growing surface and also into the films. The atomic hydrogen also enhances the surface diffusion of radicals like $\mathrm{SiH}_{3}$. Hydrogen exchange reaction also causes the local heating on the growing surface [21]. The bonding energy of $\mathrm{Si}-\mathrm{Si}(2.2 \mathrm{eV})$ bond is relatively smaller than the energy of $\mathrm{Si}-\mathrm{H}(3.4 \mathrm{eV})$; therefore, one can say that diffusing $\mathrm{H}$ can break the weak Si-Si bond. In the a-Si:H layers, silicon dangling bonds or vacancies were occupied by mostly hydrogen [63]. However, at deposition temperature of $200^{\circ} \mathrm{C}$, poly-hydrides are formed by some of the hydrogen atoms/molecules in the a-Si:H films, which sit on the inner surfaces of nano/micro-sized voids. Hence, the void size increases; this suggests that the surface roughness could be originate from the voids. It suggests that the gas is molecules of $\mathrm{H}_{2}$ and supported by several reports of experimental and theoretical research [63-65]. In equilibrium state at $200^{\circ} \mathrm{C}$, the $\mathrm{H}_{2}$ molecules can leave the voids during the deposition process and the remained free silicon bonds are recombined by the formation of the nano/micro-crystalline phase. These energetic precursors occupy more stable and favourable sites. The hydrogen atoms also etch out some amorphous fraction [66]. This results in evolution of more ordered nano/micro-crystalline phase. However, when large amount of atomic hydrogen is present during growth, film quality starts to degrade and defects formation start in growing film. In our 
case, an improvement in film microstructure, and bonding configuration of $\mathrm{Si}-\mathrm{H}$ is observed up to $60 \mathrm{SCCM}$ of HFR of a-Si:H(p) films. With further increase in HFR, increase in concentration of hydrogen atoms in plasma increases the rate of ion bombardment. This results in micro-void formation, and thus, compactness of the films is reduced. However, crystallinity has enhanced due to increase in hydrogen radical density. In SE measurements, it is manifested as a shift in peak positions and amplitude of $\left\langle\varepsilon_{2}\right\rangle$ spectra for different HFR. The best device quality films, near onset of nanocrystalline phase, are obtained for 60 SCCM of HFR. These optimized parameters are used for fabrication of c-Si(n)/a-Si:H(p) silicon-based HJ solar cells.

\section{Conclusion}

Impact of HFR on microstructural, optical properties of a-Si:H(p) films was investigated by SE measurements for solar cell applications. Microstructure of a-Si:H(p) films is improved with increase in HFR which is apparent as shift in position of peaks from 3.65 to $4.1 \mathrm{eV}$ in SE spectra and evolution of another peaks at $3.4 \mathrm{eV}$ corresponding to crystalline silicon. BEMA analysis of the SE data also confirms the increase in crystalline fraction at higher HFR. The lowest value of void fraction is obtained when HFR is 60 SCCM. These optimized parameters leading to films with enhanced microstructure and the onset of nanocrystalline phase are useful for fabrication of solar cells and for improvement of performance of the devices.

Acknowledgements Grant received from Department of Science and Technology (DST) (Grant No. DST/TM/SERI/2K11/78(G)), India, and Defence Research and Development Organization (DRDO) (Grant No. ERIP/ER/0900376/M/01/1297), India, for establishing the Multi-chamber RFPECVD system. Authors acknowledge the Central Instrument Facility (CIF), IIT Guwahati, for SE and AFM measurements.

\section{Declarations}

Conflict of interest The authors declare that they have no conflict of interest.

Open Access This article is licensed under a Creative Commons Attribution 4.0 International License, which permits use, sharing, adaptation, distribution and reproduction in any medium or format, as long as you give appropriate credit to the original author(s) and the source, provide a link to the Creative Commons licence, and indicate if changes were made. The images or other third party material in this article are included in the article's Creative Commons licence, unless indicated otherwise in a credit line to the material. If material is not included in the article's Creative Commons licence and your intended use is not permitted by statutory regulation or exceeds the permitted use, you will need to obtain permission directly from the copyright holder. To view a copy of this licence, visit http://creativecommons. org/licenses/by/4.0/.

\section{References}

1. Masuko K, Shigematsu M, Hashiguchi T, Fujishima D, Kai M, Yoshimura N, Yamaguchi T, Ichihashi Y, Mishima T, Matsubara $\mathrm{N}$, Yamanishi T, Takahama T, Taguchi M, Maruyama E, Okamoto $S$ (2014) Achievement of more than 25\% conversion efficiency with crystalline silicon heterojunction solar cell. IEEE J Photovolt 4:1433-1435. https://doi.org/10.1109/JPHOTOV.2014.2352151

2. Taguchi M, Yano A, Tohoda S, Matsuyama K, Nakamura Y, Nishiwaki T, Fujita K, Maruyama E (2014) 24.7\% Record efficiency HIT solar cell on thin silicon wafer. IEEE J Photovolt 4:96-99. https:// doi.org/10.1109/JPHOTOV.2013.2282737

3. Tsunomura Y, Yoshimine Y, Taguchi M, Baba T, Kinoshita T, Kanno H, Sakata H, Maruyama E, Tanaka M (2009) Twenty-two percent efficiency HIT solar cell. Sol Energy Mater Sol Cells 93:670-673. https://doi.org/10.1016/j.solmat.2008.02.037

4. Green MA, Hishikawa Y, Baillie AWYH, Dunlop ED, Levi DH (2018) Solar cell efficiency tables (version 51). Prog Photovolt Res Appl 26:3-12. https://doi.org/10.1002/pip.2978

5. Madaka R, Kanneboina V, Agarwal P (2018) Enhanced performance of amorphous silicon solar cells $\left(110^{\circ} \mathrm{C}\right)$ on flexible substrates with a-SiC: $\mathrm{H}(\mathrm{p})$ window layer and $\mathrm{H} 2$ plasma treatment at $n / i$ and $i / p$ interface. Semicond Sci Technol 33:3

6. Gogoi P, Agarwal P (2009) Structural and optical studies on hot wire chemical vapour deposited hydrogenated silicon films at low substrate temperature. Sol Energy Mater Sol Cells 93:199205. https://doi.org/10.1016/j.solmat.2008.09.058

7. Kroll U, Meier J, Shah A, Mikhailov S, Weber J (1996) Hydrogen in amorphous and microcrystalline silicon films prepared by hydrogen dilution. J Appl Phys 80:4971-4975. https://doi.org/ 10.1063/1.363541

8. Hamui L, Monroy BM, Kimb KH, López-Suárez A, Santoyo-Salazar J, López-López M, Roca i Cabarrocas P, Santana G (2016) Effect of deposition temperature on polymorphous silicon thin films by PECVD: role of hydrogen. Mater Sci Semicond Process 41:390397. https://doi.org/10.1016/j.mssp.2015.10.005

9. Song C, Wang X, Huang R, Song J, Guo Y (2013) Effects of doping concentration on the microstructural and optoelectrical properties of boron doped amorphous and nanocrystalline silicon films. Mater Chem Phys 142:292-296. https://doi.org/10.1016/j. matchemphys.2013.07.017

10. Westra JM, Van Swaaij RACMM, Sharma PŠK, Creatore M, Zeman $M$ (2014) Study of the effect of boron doping on the solid phase crystallisation of hydrogenated amorphous silicon films. Thin Solid Films 568:38-43. https://doi.org/10.1016/j.tsf.2014.07.040

11. Hou G, Fang J, Hua Q, Wei C, Ni J (2015) Nanostructured silicon p-layer obtained by radio frequency power pro fi ling process for high efficiency amorphous silicon solar cell. Sol Energy Mater Sol Cells 134:395-399. https://doi.org/10.1016/j.solmat.2014.12. 017

12. Wang F, Zhang X, Wang L, Fang J, Wei C (2014) Boron doped nanocrystalline silicon/amorphous silicon hybrid emitter layers used to improve the performance of silicon heterojunction solar cells. Sol Energy 108:308-314. https://doi.org/10.1016/j.solener. 2014.06.035

13. Hong JE, Oh JH, Kim KH (2020) Influence of hydrogen dilution and doping gas on the material properties of plasma-deposited polycrystalline silicon thin films. Thin Solid Films 709:138220. https://doi.org/10.1016/j.tsf.2020.138220

14. Kanneboina V, Agarwal P (2019) Role of hydrogen flow rate on microstructure of a-Si:H(n) films: spectroscopic ellipsometry studies. J Electron Mater 48:2404-2410. https://doi.org/10.1007/ s11664-019-06965-6

15. Martín De Nicolás S, Coignus J, Favre W, Kleider JP, Muñoz D (2013) N-type a-Si:H layers applied to the back side of 
heterojunction solar cells: experimental and simulation analysis. Sol Energy Mater Sol Cells 115:129-137. https://doi.org/10. 1016/j.solmat.2013.03.010

16. Myong SY, Jeon LS (2014) N-type amorphous silicon-based bilayers for cost-effective thin-film silicon photovoltaic devices. Curr Appl Phys 14:151-155. https://doi.org/10.1016/j.cap.2013.10. 021

17. Kesarwani AK, Panwar OS, Tripathi RK, Dalai MK, Chockalingam S (2015) Investigations on phosphorus doped amorphous/ nanocrystalline silicon films deposited by a filtered cathodic vacuum arc technique in the presence of hydrogen gas. Mater Sci Semicond Process 31:1-9. https://doi.org/10.1016/j.mssp. 2014.11.015

18. De Wolf S, Descoeudres A, Holman ZC, Ballif C (2012) High-efficiency silicon heterojunction solar cells: a review. Green 2:7-24. https://doi.org/10.1515/green-2011-0018

19. Madaka R, Kumari J, Venkanna Kanneboina HS, Jha PA (2019) Role of chamber pressure on crystallinity and composition of silicon films using silane and methane as precursors in hotwire chemical vapour deposition technique. Thin Solid Films 682:126-130. https://doi.org/10.1016/j.tsf.2019.04.038

20. Gullanar MH, Chen H, Wei WS, Cui RQ, Shen WZ (2004) Roles of hydrogen dilution on the microstructural and optoelectronic properties of B-doped nanocrystalline Si:H thin films. J Appl Phys 95:3961. https://doi.org/10.1063/1.1664028

21. Matsuda A (2004) Microcrystalline silicon. Growth and application. J Non Cryst Solids 338-340:1-12. https://doi.org/10.1016/j. jnoncrysol.2004.02.012

22. Hamui L, Monroy BM, Kim KH, López-Suárez A, Santoyo-Salazar J, López-López M, Roca i Cabarrocas P, Santana G (2016) Effect of deposition temperature on polymorphous silicon thin films by PECVD: role of hydrogen. Mater Sci Semicond Process 41:390397. https://doi.org/10.1016/j.mssp.2015.10.005

23. Fujiwara $H(200)$ Spectroscopic ellipsometry principles and applications. DOI: https://doi.org/10.1002/9780470060193. ISBN: 9780470016084

24. Chu Y-H, Chien-Chieh Lee I-CC, Chang S-Y, Chang J-Y, Li T (2014) Investigation of hydrogenated amorphous silicon as passivation layer by high density plasma. Thin Solid Films 570:591-594. https://doi.org/10.1016/j.tsf.2014.03.064

25. Dahal LR, Li J, Stoke JA, Huang Z, Shan A, Ferlauto AS, Wronski CR, Collins RW, Podraza NJ (2014) Applications of real-time and mapping spectroscopic ellipsometry for process development and optimization in hydrogenated silicon thin-film photovoltaics technology. Sol Energy Mater Sol Cells 129:32-56. https://doi. org/10.1016/j.solmat.2014.01.028

26. Hadjadj A, Djellouli G, Jbara O (2010) In situ ellipsometry study of the kinetics of hydrogen plasma interaction with a-Si: $\mathrm{H}$ thin films: a particular temperature-dependence. Appl Phys Lett 97:28-31. https://doi.org/10.1063/1.3517495

27. Nguyen HV, An I, Collins RW, Lu Y, Wakagi M, Wronski CR (1994) Preparation of ultrathin microcrystalline silicon layers by atomic hydrogen etching of amorphous silicon and end-point detection by real time spectroellipsometry. Appl Phys Lett 65:33353337. https://doi.org/10.1063/1.113024

28. Fujiwara H, Collins RW (2018) Spectroscopic ellipsometry for photovoltaics volume 1: fundamental principles and solar cell characterization. Springer. https://doi.org/10.1007/ 978-3-319-95138-6

29. Fujiwara $\mathrm{H}$ (2018) Amorphous/crystalline Si heterojunction solar cells. In: Fujiwara H, Collins R (eds) Spectroscopic ellipsometry for photovoltaics. Springer International Publishing, pp 227252. https://doi.org/10.1007/978-3-319-75377-5

30. Fujiwara H, Collins RW (2018) Spectroscopic ellipsometry for photovoltaics volume 2: applications and optical data of solar cell materials. http://www.springer.com/series/624
31. Zhang H, Zhang X, Hou G, Wei C, Sun J, Geng X, Xiong S, Zhao $Y$ (2012) The microstructure and optical properties of p-type microcrystalline silicon thin films characterized by ex-situ spectroscopic ellipsometry. Thin Solid Films 521:17-21. https://doi. org/10.1016/j.tsf.2012.03.081

32. Yuguchi T, Kanie Y, Matsuki N, Fujiwara H (2012) Complete parameterization of the dielectric function of microcrystalline silicon fabricated by plasma-enhanced chemical vapor deposition. J Appl Phys 111:083509. https://doi.org/10.1063/1.47041 58

33. Huang Z, Dahal LR, Marsillac S, Podraza NJ, Collins RW (2018) Real time and mapping spectroscopic ellipsometry of hydrogenated amorphous and nanocrystalline Si solar cells. Springer International Publishing. https://doi.org/10.1007/ 978-3-319-95138-6_7

34. Collins RW, Ferlauto AS, Ferreira GM, Chen C, Koh J, Koval RJ, Lee Y, Pearce JM, Wronski CR (2003) Evolution of microstructure and phase in amorphous, protocrystalline, and microcrystalline silicon studied by real time spectroscopic ellipsometry. Sol Energy Mater Sol Cells 78:143-180. https://doi.org/10. 1016/S0927-0248(02)00436-1

35. Jellison GE, Modine FA (1996) Parameterization of the optical functions of amorphous materials in the interband region. Appl Phys Lett 69:371-373. https://doi.org/10.1063/1.118064

36. Kageyama S, Akagawa M, Fujiwara H (2011) Dielectric function of a-Si:H based on local network structures. Phys Rev B 83:195205. https://doi.org/10.1103/PhysRevB.83.195205

37. Koirala $P$, Attygalle $D$, Aryal $P$, Pradhan $P$, Chen J, Marsillac $S$, Ferlauto AS, Podraza NJ, Collins RW (2014) Real time spectroscopic ellipsometry for analysis and control of thin film polycrystalline semiconductor deposition in photovoltaics. Thin Solid Films 571:442-446. https://doi.org/10.1016/j.tsf.2013.10. 158

38. Fontcuberta i Morral A, Roca i Cabarrocas P, Clerc C (2004) Structure and hydrogen content of polymorphous silicon thin films studied by spectroscopic ellipsometry and nuclear measurements. Phys Rev B 69:125307. https://doi.org/10.1103/PhysR evB.69.125307

39. Morral FI, Roca i Cabarrocas P (2002) Etching and hydrogen diffusion mechanisms during a hydrogen plasma treatment of silicon thin films. J Non Cryst Solids 299-302:196-200. https:// doi.org/10.1016/S0022-3093(01)01001-8

40. Ferlauto AS, Rovira PI, Koval RJ, Wronski CR, Collins RW (2000) Study of the amorphous-to-microcrystalline transition during silicon film growth at increased rates: extensions of the evolutionary phase diagram. Mater Res Soc Symp Proc 609:1-6. https://doi.org/10.1557/proc-609-a2.2

41. Venkanna Kanneboina R, Madaka PA (2018) Spectroscopic ellipsometry studies on microstructure evolution of a-Si:H to nc-Si: $\mathrm{H}$ films by H2 plasma exposure. Mater Today Commun 15:18-29. https://doi.org/10.1016/j.mtcomm.2018.02.023

42. Venkanna Kanneboina R, Madaka PA (2018) High open circuit voltage c-Si/a-Si:H heterojunction solar cells: influence of hydrogen plasma treatment studied by spectroscopic ellipsometry. Sol Energy 166:255-266. https://doi.org/10.1016/j.solener.2018. 03.068

43. Kushner MJ (1988) A model for the discharge kinetics and plasma chemistry during plasma enhanced chemical vapor deposition of amorphous silicon. J Appl Phys 63:2532-2551. https://doi.org/10.1063/1.340989

44. Matsuda A, Takai M, Nishimoto T, Kondo M (2003) Control of plasma chemistry for preparing highly stabilized amorphous silicon at high growth rate. Sol Energy Mater Sol Cells 78:3-26. https://doi.org/10.1016/S0927-0248(02)00431-2 
45. Wilfried GJ, van Sark HM (2002) Methods of deposition of hydrogenated amorphous silicon for device applications. Thin Film Nanostruct. https://doi.org/10.1016/S1079-4050(02)80004-7

46. Kageyama S, Akagawa M, Fujiwara H (2012) Ellipsometry characterization of a-Si:H layers for thin-film solar cells. J Non Cryst Solids 358:2257-2259. https://doi.org/10.1016/j.jnoncrysol. 2011.12.042

47. Bruggeman DAG (1935) Berechnung verschiedener physikalischer Konstanten von heterogenen Substanzen. I. Die elastischen Konstanten der quasiisotropen Mischkorper aus isotropen Substanzen. Ann Phys 416:636-664. https://doi.org/10.1002/andp. 19374210205

48. Aspnes DE (1982) Optical properties of thin films. Thin Solid Films 89:249-262. https://doi.org/10.1016/0040-6090(82) 90590-9

49. Tauc J, Grigorovici R, Vancu A (1966) Optical properties and electronic structure of amorphous germanium. Phys Status Solidi 15:627-637. https://doi.org/10.1002/pssb.19660150224

50. Tauc J, Menth A (1972) States in the gap. J Non Cryst Solids 8-10:569-585. https://doi.org/10.1016/0022-3093(72)90194-9

51. Zhao L, Zhao B, Yan B, Diao H, Mao Y (2013) Pressure on p-type a-Si:H window layer doped by trimethylboron for a-Si:H superstrate solar cell in plasma enhanced chemical vapor deposition. Mater Sci Semicond Process 16:363-368. https://doi.org/10. 1016/j.mssp.2012.08.013

52. Li X, Li L, Ma Z, Lu J, Volinsky AA, Ren F (2016) Boron doping effects on microcrystalline silicon film roughness studied by spectroscopic ellipsometry. J Alloys Compd 684:582-586. https://doi.org/10.1016/j.jallcom.2016.05.212

53. Zhong CL, Luo LE, Tan HS, Geng KW (2014) Band gap optimization of the window layer in silicon heterojunction solar cells. Sol Energy 108:570-575. https://doi.org/10.1016/j.solener.2014.08. 010

54. Das D, Bhattacharya K (2006) Characterization of the Si:H network during transformation from amorphous to micro- and nanocrystalline structures. J Appl Phys 100:103701. https://doi. org/10.1063/1.2384812

55. Danesh P, Pantchev B, Antonova K, Liarokapis E, Schmidt B, Grambole D, Baran J (2004) Hydrogen bonding and structural order in hydrogenated amorphous silicon prepared with hydrogen-diluted silane. J Phys D Appl Phys 37:249-254. https://doi. org/10.1088/0022-3727/37/2/013

56. Müllerová J, Šutta P, van Elzakker G, Zeman M, Mikula M (2008) Microstructure of hydrogenated silicon thin films prepared from silane diluted with hydrogen. Appl Surf Sci 254:3690-3695. https://doi.org/10.1016/j.apsusc.2007.10.069

57. Zeman M, van Elzakker G, Tichelaar FDD, Sutta P (2009) Structural properties of amorphous silicon prepared from hydrogendiluted silane. Philos Mag 89:2435-2448. https://doi.org/10. 1080/14786430902960137
58. Funde AM, Bakr NA, Kamble DK, Hawaldar RR, Amalnerkar DP, Jadkar SR (2008) Influence of hydrogen dilution on structural, electrical and optical properties of hydrogenated nanocrystalline silicon (nc-Si:H) thin films prepared by plasma enhanced chemical vapour deposition (PE-CVD). Sol Energy Mater Sol Cells 92:1217-1223. https://doi.org/10.1016/j.solmat.2008.04.012

59. Wang SH, Chang HE, Lee CC, Fuh YK, Li TT (2020) Evolution of a-Si:H to nc-Si:H transition of hydrogenated silicon films deposited by trichlorosilane using principle component analysis of optical emission spectroscopy. Mater Chem Phys 240:122186. https://doi.org/10.1016/j.matchemphys.2019.122186

60. Chakraborty M, Banerjee A, Das D (2014) Spectroscopic studies on nanocrystalline silicon thin films prepared from $\mathrm{H} 2$-diluted $\mathrm{SiH} 4$-plasma in inductively coupled low pressure RF PECVD. Phys E Low-Dimens Syst Nanostruct 61:95-100. https://doi.org/ 10.1016/j.physe.2014.03.016

61. Goswami R, Ray S (2013) Structural studies on Si:H network before and after solid phase crystallization using spectroscopic ellipsometry: correlation with Raman spectroscopy and transmission electron microscopy. Appl Surf Sci 282:615-623. https:// doi.org/10.1016/j.apsusc.2013.06.021

62. Kalas $B$, Zolnai $Z$, Sáfrán $G$, Serényi $M$, Agocs $E$, Lohner T, Nemeth A, Khánh NQ, Fried M, Petrik P (2020) Micro-combinatorial sampling of the optical properties of hydrogenated amorphous Si1-xGex for the entire range of compositions towards a database for optoelectronics. Sci Rep. https://doi.org/10.1038/ s41598-020-74881-5

63. Street RA (1991) Hydrogenated amorphous silicon. DOI: https:// doi.org/10.1017/CBO9780511525247. ISBN: 9780521371568

64. Beyer W (2003) Diffusion and evolution of hydrogen in hydrogenated amorphous and microcrystalline silicon. Sol Energy Mater Sol Cells 78:235-267. https://doi.org/10.1016/S09270248(02)00438-5

65. Frigeri C, Serényi M, Szekrényes Z, Kamarás K, Csik A, Khánh NQ (2015) Effect of heat treatments on the properties of hydrogenated amorphous silicon for PV and PVT applications. Sol Energy 119:225-232. https://doi.org/10.1016/j.solener.2015.07.004

66. Remes Z, Vanecek M, Torres P, Kroll U, Mahan AH, Crandall RS (1998) Optical determination of the mass density of amorphous and microcrystalline silicon layers with different hydrogen contents. J Non Cryst Solids 227-230:876-879. https://doi.org/10. 1016/S0022-3093(98)00207-5

Publisher's Note Springer Nature remains neutral with regard to jurisdictional claims in published maps and institutional affiliations. 